\title{
O USO DO MARKETING DE RELACIONAMENTO ALIADO A TECNOLOGIA DA INFORMAÇÃO EM UMA FÁBRICA DE SOFTWARE
}

\section{1- Emerson Antonio Maccari \\ Universidade Nove de Julho - UNINOVE \\ emersonmaccari@gmail.com}

\section{3- Reno Bennertz \\ Universidade de Blumenau - FURB \\ renobennertz@pop.com.br}

\section{5- Maurício S. de Azevedo \\ Universidade Nove de Julho - UNINOVE \\ mauricio@izatravel.com.br}

\author{
2- Nadia Kassouf Pizzinatto \\ Universidade Nove de Julho - UNINOVE \\ nkp@merconet.com.br
}

\author{
4- Cibele Barsalini Martins \\ Universidade Nove de Julho - UNINOVE \\ cibelebm@uol.com.br
}

\section{RESUMO}

O objetivo deste trabalho foi identificar fatores de satisfação considerados importantes pelos clientes no atendimento prestado por uma fábrica de Software e, como em função deles, ela define suas estratégias de marketing de relacionamento. O método de pesquisa foi o quantitativo com o uso de um questionário estruturado com 123 clientes combinado com a pesquisa qualitativa em profundidade com os dirigentes da fábrica de software. Os resultados indicam que a empresa vem aplicando as práticas do marketing de relacionamento com o suporte da Tecnologia da Informação - TI. Como consequência, ela vem obtendo resultados positivos nos seguintes aspectos: a) qualidade no atendimento; b) agilidade na solução de problemas; c) competência na solução apontada; d) disponibilidade e rapidez no pronto atendimento; e) pós-atendimento eficiente; f) custo benefício do serviço prestado; e g) profissionalismo da equipe de suporte.

\section{Palavras-Chave}

Palavras-chave: Marketing de Relacionamento, Tecnologia da Informação, Fábrica de software.

\section{ABSTRACT}

The objective of this study was to identify satisfaction factors considered important by customers in the service provided by a software factory, and as a function of them, the company defines its strategies of relationship marketing. The research method was quantitative using a structured questionnaire with 123 clients combined with a depth qualitative research with the leaders of the software factory. The results indicate that the company has applied the practices of relationship marketing with the support of Information Technology - IT. In fact, it has achieved positive results in the following aspects: a) quality of service, b) speed in solves the problems; c) expertise in the solution indicated d) availability and speed in a solution; e) quality in after service; f) cost-effective in a service provided; g) professional support staff.

\section{Keywords}

Keywords: Relationship Marketing, Information Technology, software factory. 


\section{Introdução}

Com a competição atual, a necessidade de conhecer melhor os clientes tem se tornado essencial para o sucesso das organizações, pois elas podem adaptar mais rapidamente seus produtos e serviços para melhor atendê-los. Para isso, o Marketing de Relacionamento vem se configurando fundamental em organizações para conhecer e atender de forma efetiva seus clientes. A idéia é simples, mas o seu funcionamento na prática não é tão fácil assim. De acordo com Stone (1998), Marketing de Relacionamento é "o uso de uma ampla gama de técnicas e processos de marketing, vendas, comunicação e cuidado com o cliente para: 1) identificar seus clientes de forma individualizada e nominal; 2) criar um relacionamento que se prolongue por muitas transações entre a empresa e esses clientes; e 3) administrar esse relacionamento para o benefício de ambos.

Neste sentido, a melhor maneira de se implantar o Marketing de Relacionamento é por meio dos serviços prestados pela organização, os quais agregam valor de modo a refletir as expectativas dos clientes. Essa agregação pode ocorrer tanto na venda de bens tangíveis (produtos) como de bens intangíveis (serviços). Las Casas (2006, p. 17) define serviços (enquanto bem intangível) com sendo "uma transação realizada por uma empresa ou por um individuo, cujo objetivo não está associado à transferência de bem". O autor cita ainda que a Associação Americana de Marketing define serviços como "aquelas atividades, vantagens ou mesmo satisfações que são oferecidas à venda ou que são proporcionadas em conexão com a venda de mercadorias".

Os serviços representam cada vez mais uma parte importante da economia; no Brasil, correspondem a 55\% do Produto Interno Bruto (PIB). Já nos Estados Unidos e no Canadá, respondem por $72 \%$ e $67 \%$ do PIB, respectivamente. Além disso, o setor de serviços é responsável pela maior parte do crescimento dos novos empregos, sendo que à medida que uma economia nacional se desenvolve, a participação do emprego na agricultura, indústria e nos serviços, muda drasticamente. (LOVELOCK, 2001; LAS CASAS, 2006; GRÖNROOS, 2009).

Nesse sentido, estudar o Marketing de Relacionamento e suas implicações na prestação de serviço vislumbra-se importante, principalmente quando se aborda um setor extremamente dinâmico que é justamente o da indústria de produção de software. Assim, esse artigo tem por objetivo identificar fatores de satisfação considerados importantes no atendimento prestado ao cliente por uma fábrica de Software e como, em função deles, ela define as estratégias de marketing de relacionamento com o cliente.

\section{0 turismo e a baixa renda no Brasil}

A indústria brasileira de software segue a tendência de crescimento tecnológica mundial que, conforme Nunes (2004), esse mercado vem crescendo em média $11 \%$ ao ano desde 1995. Nesse sentido, as empresas nacionais vêm desenvolvendo sistemas aplicativos de diversas finalidades voltadas para os mais variados tipos de clientes como: industriais comerciais e indivíduos.

O Brasil, em 2001, possuía cerca de 320 mil profissionais em organizações que desenvolvem serviços e produtos de software (empresas de informática ou não), dos quais 59 mil envolvidos com atividades de pesquisa e desenvolvimento (P\&D), (AGTECH, 2007).

A capacidade brasileira de gerar sistemas aplicativos de elevada sofisticação tecnológica é comprovada pelos inúmeros sistemas administrativos existentes no mercado. Segundo o SOFTEX (2000), dentre os atributos do software brasileiro, destacam-se a qualidade, flexibilidade, design, criatividade e inovação.

O crescimento das empresas brasileiras do setor indica um perfil competitivo mesmo dependendo de avanços tecnológicos externos, em que certas características contribuem para isso. Nessa linha, de acordo com o SEBRAE (2007) é possível identificar algumas características do setor brasileiro, como, por exemplo, a predominância de micros e pequenas empresas, que atendem basicamente ao mercado interno e que alcançam elevado grau de satisfação dos clientes.

Nesse contexto, o Estado de Santa Catarina se destaca na produção nacional de software, sendo líder no segmento de projetos prediais e soluções para gerenciamento de filas em bancos privados, (FIESC, 2008). A pujança do setor de informática do Estado Catarinense é verificada quando se comparado com os dados do Brasil, (vide tabela 1). 
Tabela 1 - Setor de informática de Santa Catarina e Brasil

\begin{tabular}{|c|c|c|c|}
\hline Descrição & $\begin{array}{c}\mathrm{N}^{\circ} \text { de } \\
\text { empregados }\end{array}$ & $\begin{array}{c}\mathbf{N}^{\circ} \text { de } \\
\text { estabelecimentos }\end{array}$ & $\begin{array}{l}\text { Rendimentos } \\
\text { (em R\$) }\end{array}$ \\
\hline A) Setor de informática - SC & 12.341 & 1.315 & 13.142 .607 \\
\hline (i) Consultoria em hardware & 642 & 72 & 848.557 \\
\hline (ii) Desenvolvimento software pronto para uso & 844 & 86 & 1.278 .768 \\
\hline (iii) Desenvolvimento de software sob encomenda & 1.451 & 119 & 2.021 .853 \\
\hline (iv) Processamento de dados & 6.965 & 625 & 5.025 .964 \\
\hline (v) Atividades de banco de dados & 103 & 18 & 87.797 \\
\hline (vi) Manutenção e reparação de máquinas de informática & 670 & 162 & 569.949 \\
\hline (vii) Outras atividades de informática & 1.666 & 233 & 3.309 .719 \\
\hline B) Setor de informática - Brasil & 219.321 & 17.617 & 379.201 .420 \\
\hline (i) Consultoria em hardware & 32.770 & 1.631 & 75.188 .327 \\
\hline (ii) Desenvolvimento de software pronto para uso & 8.193 & 658 & 13.950 .450 \\
\hline (iii) Desenvolvimento de software sob encomenda & 26.511 & 1.242 & 57.262 .792 \\
\hline (iv) Processamento de dados & 73.672 & 7.031 & 96.361 .537 \\
\hline (v) Atividades de banco de dados & 6.099 & 207 & 16.267 .483 \\
\hline (vi) Manutenção e reparação de máquinas de informática & 22.097 & 2.624 & 34.593 .240 \\
\hline (vii) Outras atividades de informática & 49.979 & 4.224 & 85.577 .592 \\
\hline C) Total de atividades econômicas - SC & 1.486 .969 & 133.731 & 1.411.992.556 \\
\hline D) Total de atividades econômicas - Brasil & 33.238.617 & 2.427.488 & 35.861.972.723 \\
\hline
\end{tabular}

Participação do subsetor de software no setor de informática (em \%)

\begin{tabular}{|c|c|c|c|}
\hline Santa Catarina & Empregados & Estabelecimentos & Rendimentos \\
\hline Subsetor software - SC & 75,0 & 63,1 & 63,4 \\
\hline Desenvolvimento de software pronto para uso & 6,8 & 6,5 & 9,7 \\
\hline Desenvolvimento de software sob encomenda & 11,8 & 9,0 & 15,4 \\
\hline Processamento de dados & 56,4 & 47,5 & 38,2 \\
\hline
\end{tabular}

Participação do subsetor de software no setor de informática (em \%)

\begin{tabular}{|c|c|c|c|}
\hline Brasil & Empregados & Estabelecimentos & Rendimentos \\
\hline Subsetor software - Brasil & 49,4 & 50,7 & 44,2 \\
\hline Desenvolvimento de software pronto para uso & 3,7 & 3,7 & 3,7 \\
\hline Desenvolvimento de software sob encomenda & 12,1 & 7,1 & 15,1 \\
\hline Processamento de dados & 33,6 & 39,9 & 25,4 \\
\hline
\end{tabular}

Fonte: Panorama do Setor de Software de Santa Catarina - SEBRAE/SC (2007) - Elaboração Funcex a partir de dados da

Rais/MTE (2005)

Ainda conforme FIESC (2008) o estado catarinense registrou, até 2007, 1.600 empresas estabelecidas, sendo o único estado do país a possuir cinco pólos tecnológicos com faturamento de $\mathrm{R} \$ 1,5$ bilhões e 17 mil empregos diretos. Cabe destacar a importância da cidade de Blumenau como o maior pólo do Estado com aproximadamente 300 empresas de base tecnológica, totalizando um faturamento de $\mathrm{R} \$ 650$ milhões e gerando mais de 5.100 empregos diretos.

Assim, o binômio dedicação ao produto (tecnologia de processo e produto) e interesse pelo cliente (mercado e segmentação), parece ser fundamental para o próximo passo a ser dado pelas empresas. Dessa forma, as ferramentas do Marketing de Relacionamento aliadas à tecnologia da informação apresentam-se como parte das soluções possíveis.

\section{Marketing de Relacionamento}

Para Mowen e Minor (2003) e Seth, Mittal e Newman (2001) compreender o comportamento do consumidor pode ser fator determinante no sucesso ou fracasso da organização. Seu estudo oferece informações importantes para o processo decisório e elaborar o planejamento estratégico e de marketing.

Nessa linha, o Marketing de Relacionamento é um enfoque do marketing que se baseia no comportamento do consumidor. Apesar do destaque do assunto nos últimos anos, Grönroos (2009) afirma que a expressão Marketing de Relacionamento (MR) foi introduzido na literatura acadêmica em 1983 por Leonard Berry e passou a ser bastante discutido apenas dez anos depois, definindo da seguinte forma: 
(cooperação e interdependia em vez de conflitos e escolhas independentes). Assim, o marketing de relacionamento é, antes de tudo, uma perspectiva de como a empresa pode se relacionar com seus clientes e outras partes, de modo a causar um impacto sobre como o negócio é desenvolvido e os clientes são gerenciados, (GRÖNROOS, 2009, p. 39).

D'angelo, Schneider e Larán (2006, p. 73) afirma que "o marketing de relacionamento é uma filosofia empresarial que prevê a construção e a manutenção de relacionamentos individuais com os clientes, vislumbrando um horizonte de longo prazo". Esse autor destaca ainda que os serviços adicionais tendem a desempenhar um papel fundamental na formação e sustentação de relações entre a empresa e o cliente. A empresa necessita conhecer melhor os clientes, para com isto poder oferecer o serviço adequado e conseqüentemente aumentar o relacionamento com o mesmo.

Nesse sentido, Marinho (2002) reforça a idéia dizendo que o relacionamento é algo estabelecido entre a marca e pessoas. Uma vez identificados a identidade da marca e o perfil do consumidor, cabe ao marketing de relacionamento garantir esta ligação num processo contínuo de ação e reação. A empresa age de uma forma e o cliente reage de forma positiva ou negativa. Quanto mais o cliente perceber que a empresa sabe reconhecer suas necessidades e entregar o produto ou serviços compatíveis com as suas características, mais informações cedem a seu respeito. E quanto mais informações a empresa tiver, maior a capacidade de reconhecer e privilegiar estes clientes.

Assim, o marketing de relacionamento admite que o consumidor é um agente ativo no que tange o processo de troca, diferentemente do que apontam as abordagens tradicionais de marketing em que a empresa é o agente ativo e o consumidor é considerado apenas um agente passivo a ser manipulado - ele pode ser influenciado, mas não manipulado (LOURENÇO; PEREIRA, 2007).

A rigor, é natural que o tema Marketing de Relacionamento tenha mais destaque nas empresas prestadoras de serviços, posto que o contato com o consumidor final é mais intenso,fazendo assim surgir o relacionamento. A questão principal se dá a partir do momento em que esse relacionamento deixa de ser satisfatório para o cliente cessando assim o processo de compra.

A satisfação nesse contexto é considerada um dos principais fatores para a manutenção de clientes, sendo o resultado de um julgamento a respeito do seu contentamento em relação a determinado produto ou serviço. Esse processo é feito por meio da comparação entre expectativas anteriores e se suas percepções de valores posteriores, sendo assim um dos processos mais importantes na atividade mercadológica da organização (KOTLER; KELLER, 2006; DE TONI et al, 2008).

Stone (1998) diz que os clientes ficam satisfeitos em obter o produto e ao mesmo tempo esperam um padrão razoável de atendimento dos fornecedores dos novos produtos, mesmo que estes não sejam melhores. A colocação a venda de produtos que atendam as necessidades dos clientes e que gerem lucro para o fornecedor são os fatores chave no mercado competitivo.

Ainda segundo o autor, o princípio dominante do Markting de Relacionamento é a orientação para o cliente. Isto não significa dar tudo para ele, significa identificar suas necessidades e atendê-las com lucro. No limite, a orientação para ao cliente não é apenas uma atitude mental, trata-se de toda uma maneira da empresa pensar e agir, fazendo parte de sua cultura organizacional.

\section{O Marketing de Relacionamento e a Tecnologia da Informação}

A combinação do Marketing de Relacionamento com a Tecnologia da Informação (TI), cria, sustenta, desenvolve, mantém e interpreta um bom relacionamento de marketing e serviços para com seus clientes a custos menores, (STONE, 1998). A partir dessas ferramentas, a manutenção dos clientes torna-se muito mais efetiva, pois de acordo com Stone (1998, p. 1), "ganhar novos clientes custa mais caro do que os manter". Nessa linha, investir em TI diminui os custos de comunicação, contribuindo de forma mais efetiva para a concepção e aprimoramento de produtos e serviços personalizados.

É importante destacar que as mudanças ocorridas no marketing de relacionamento devido ao uso da TI. O seu uso dessas ferramentas combinadas torna mais efetivo o atendimento das expectativas dos clientes, independente do mercado de atuação da empresa seja ele comércio, indústria ou na prestação de serviços. Essa observação permite às empresas inúmeras oportunidades para conquistar novos clientes e novos mercados.

Para Mckenna (1992) a importância da Tecnologia da Informação (TI) para o MR vai muito além de softwares ou hardwares complexos necessários para o processamento das 
informações. O grande destaque está na capacidade de gerir importantes informações que devem ser interpretadas para uma tomada de decisão mais eficaz com menor probabilidade de erro auxiliando os gestores no planejamento estratégico das organizações.

Essas informações são coletadas, processadas e disponibilizadas pelo Sistemas de Informações (SI) da empresa, que segundo (ALBERTÃO, 2005; LAUDON; LAUDON, 2001; O'BRIEN, 2002; POLLONI, 2000; STAIR; REYNOLDS, 2009; TURBAN et al, 2003) consiste em um conjunto de elementos inter-relacionados que, de alguma forma dão suporte à tomada de decisão organizacional.

Laudon e Laudon (2001) e Cortêz (2008) afirmam que esse sistema pode dar apoio nos três níveis gerenciais: operacional (questões práticas do dia-a-dia com informações pontuais, como um cadastro de clientes utilizado por um atendente de telemarketing); tático (dados que facilitam o controle de atividades, como decisões gerenciais) e estratégicas (mais abrangentes e de longo prazo, utilizadas pela cúpula da organização).

Adicionalmente, o marketing de relacionamento, por sua vez, pode-se utilizar das informações apresentadas pelo sistema específico de Customer Relationship Management (CRM) que se baseia nas informações extraídas dos sistemas de nível estratégico ou até mesmo tático como o SIG, permitindo assim uma melhoria no relacionamento com os consumidores (Figura 1).

Figura 1 - Marketing de Relacionamento

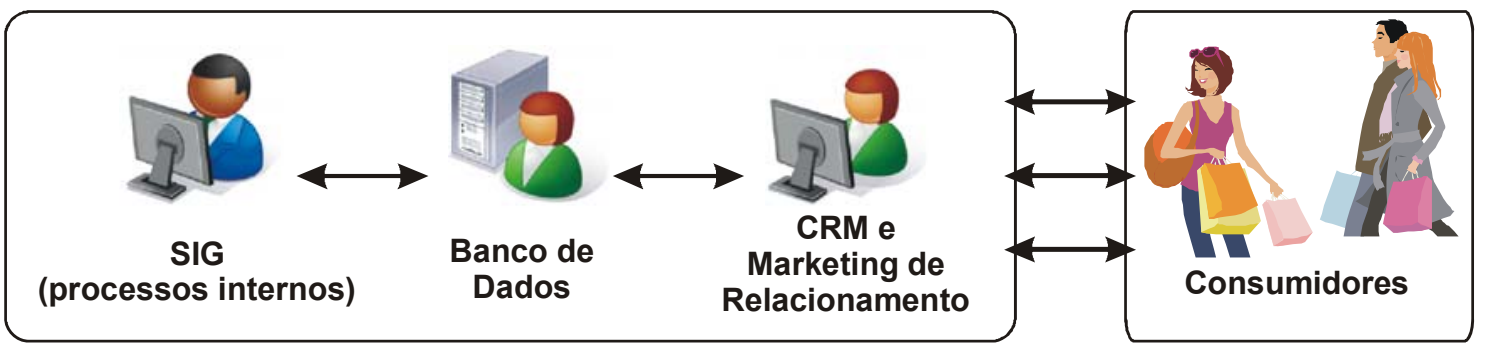

Fonte: Elaborado pelos autores com base em Cortêz (2008)

Porém o CRM sozinho não é capaz de agregar valor no relacionamento com o cliente. Ele é apenas mais uma ferramenta à disposição do MR que tem como objetivo realizar a busca $\mathrm{e}$ armazenamento de informações importantes de clientes. Ademais, ele é um facilitador do contato, manutenção e aquisição de novos clientes, por meio de pesquisas, promoções, desenvolvimento de produtos e preços. Como resultado, ele auxilia os gestores na redução de despesas e desenvolvimento de planos e serviços futuros que possam atender às necessidades dos consumidores (BROWN, 2001).

Stair e Reynolds (2009) lembram que a companhia aérea Alaska Airlines só conseguiu sobreviver à crise provocada pela queda das torres de Nova York em 11 de Setembro de 2001 graças ao software (CRM) responsáveis pelo MR em que todos os clientes foram informados pelo sistema a respeito das modificações e cancelamento dos vôos.

Outra linha defendida por Stair e Reynolds (2009) é que a utilização do CRM pelo MR está diretamente ligado à necessidade de se obter vantagem competitiva. Dessa forma, por meio de informações rápidas e privilegiadas de seus clientes, possibilita que a organização não somente venda um produto, mas também mantenha um relacionamento com o clientes por meio de contatos periódicos oferecendo outros serviços, atualizações, ou mesmo realizando uma pesquisa de mercado. (SZAFIR-GOLDSTEIN; SOUZA, 2003).

\section{Método de Pesquisa}

Para responder ao objetivo do trabalho que foi identificar fatores de satisfação considerados importantes pelos clientes no atendimento prestado por uma fábrica de Software e como, em função deles, ela define suas estratégias de marketing de relacionamento - combinamos os métodos de pesquisa quantitativa e qualitativa.

Nesse sentido, respondendo "parte" do objetivo de identificar os fatores de satisfação considerados importantes pelos clientes no atendimento prestado por uma fábrica de Software utilizamos a pesquisa quantitativa com 123 clientes. Isso se fez necessário devido a especificidades das pesquisas quantitativas que prevêem a mensuração de 
variáveis pré-estabelecidas, procurando verificar e explicar sua influência sobre outras variáveis, mediante a análise da frequência de incidências e de correlações estatísticas (CHIZZOTTI, 1995). Adicionalmente a pesquisa quantitativa é mais adequada para apurar opiniões e atitudes e conscientes dos entrevistados, pois utilizam instrumentos padronizados (questionários). Godoy (1995) afirma que na pesquisa quantitativa o pesquisador conduz seu trabalho a partir de um plano pré-estabelecido com hipóteses claramente especificadas e variáveis operacionalmente definidas.

Já para responder o "restante" do objetivo que se refere a como a Fabrica de software, em função dos fatores de satisfação revelados na pesquisa quantitativa, define as estratégias de marketing de relacionamento com o cliente, adotamos a pesquisa qualitativa com os dirigentes da empresa. Esse tipo de pesquisa na visão de Mason (1997) apresenta a característica de ser: a) sistemática e rigorosamente conduzida (contudo, sem as características das abordagens rígidas e estruturadas para testar hipóteses); b) estrategicamente gerenciada, flexível e contextual, em função da sensibilidade do pesquisador às mudanças de contexto; c) reflexiva, pois busca dados com atuação crítica do pesquisador, com base na ideia de não ficar neutro no seu papel durante o processo de pesquisa; d) combinada sem problemas com diversos métodos, inclusive os quantitativos; e) conduzida dentro do caráter ético, considerando o contexto político. Corroborando com esse autor, Samara e Barros (1997) afirmam que as pesquisas qualitativas são realizadas a partir de entrevistas individuais ou discussões em grupo, e sua análise verticalizada em relação ao objeto em estudo permita identificar pontos comuns e distintivos presentes na amostra escolhida.

O estudo foi ainda descritivo, pois teve como propósito a apresentação das características de determinada população, fenômeno, ou o estabelecimento de relações entre variáveis, sem o compromisso de explicá-los, porém servindo como base para esta explicação (VERGARA, 2004). O estudo descritivo possibilitou o desenvolvimento de um nível de análise em que se permitisse identificar as diferentes formas dos fenômenos, sua ordenação e classificação. Neste sentido, pode-se descobrir os fatores importantes do Marketing de Relacionamento de uma fábrica de software e a forma que ela administra o relacionamento com o cliente.

Como, utilizamos a técnica de pesquisa de escalograma, com um questionário fechado com escala do tipo Likert para a pesquisa quantitativa com os clientes e, um questionário semiestruturado aberto, para a pesquisa qualitativa com os dirigentes.

\subsection{População e Amostra}

A população foi composta por cerca de 4000 clientes ativos da fábrica de software. A amostra foi a não probabilística para os clientes que responderam ao questionário, sendo que obtivemos um retorno de 128 questionários. Destaca-se que descartamos cinco por não terem sido devidamente preenchidos, resultando num total de 123 válidos.

\subsection{Instrumento de Coleta dos Dados}

$\mathrm{Na}$ elaboração do instrumento de pesquisa foi levada em consideração a sua aderência aos objetivos do estudo. Assim, para descobrir os fatores de satisfação considerados importantes pelos clientes no atendimento prestado pela fábrica de software foi conduzida uma pesquisa por meio de questionário estruturado composto por questões fechadas. As informações tomaram por base a percepção dos clientes respondentes em relação a cada pergunta com as seguintes opções de resposta em uma escala de satisfação: 1) Totalmente Insatisfeito; 2) Insatisfeito; 3) Indiferente; 4) Satisfeito; 5) Totalmente Satisfeito. O quadro 1 , ilustra 0 instrumento de coleta dados utilizado:

\begin{tabular}{|c|c|c|c|c|c|}
\hline \multirow{2}{*}{ Itens do questionário } & \multicolumn{5}{|c|}{ Escalas } \\
\hline & 1 & 2 & 3 & 4 & 5 \\
\hline $\begin{array}{l}\text { Qualidade do atendimento recebido considerando cordialidade, respeito, } \\
\text { educação, cortesia pessoal, agilidade e presteza necessária? }\end{array}$ & & & & & \\
\hline $\begin{array}{l}\text { Agilidade na solução do problema, responsabilidade e credibilidade com os } \\
\text { compromissos assumidos com o cliente? }\end{array}$ & & & & & \\
\hline À competência da solução apontada pelo pessoal de atendimento? & & & & & \\
\hline À disponibilidade e rapidez no pronto atendimento & & & & & \\
\hline $\begin{array}{l}\text { Ao apoio recebido do pessoal do suporte após apresentada a solução do } \\
\text { problema? }\end{array}$ & & & & & \\
\hline Custo e benefício dos produtos e serviços prestados? & & & & & \\
\hline Profissionalismo e compromisso da equipe de suporte? & & & & & \\
\hline
\end{tabular}


Após a coleta dos dados, foi realizada uma pesquisa qualitativa com os dirigentes da empresa com a intenção de cruzar os resultados obtidos no questionário com a visão deles em relação às estratégias de marketing de relacionamento adotadas pela empresa em relação aos seus clientes.

\subsection{Limitações da Pesquisa}

De acordo com Creswell (2003), descrever as limitações do estudo remete à especificação, à circunscrição do estudo em questão. Este autor afirma ainda que as formas de limitações podem ser: a) o método escolhido; b) a forma que os dados foram coletados e c) a análise dos dados. Assim, esta pesquisa delimita-se ao estudo da empresa pesquisada, não se aplicando a outros setores de atividade ou até mesmo outras empresas. Este tipo de pesquisa serve para lançar luz sobre as questões consideradas importantes no atendimento prestado por uma fábrica de software e como ela administra o seu relacionamento com o cliente.

\subsection{Caracterização do Ambiente de Pesquisa}

A WK Sistemas é uma fábrica de Software situada na cidade de Blumenau no Estado de Santa Catarina, Brasil. Tanto a cidade quanto o Estado são reconhecidos nacional e internacionalmente pela sua pujança no desenvolvimento de Tecnologia de Informação e Comunicação - TIC. Nesse cenário, a WK Sistemas ocupa um lugar de destaque, pois desde sua fundação em 1984, ela tem apresentado pioneirismo e inovações tecnológicas, aliados a uma moderna e eficiente metodologia de atendimentos ao cliente.

A empresa já comercializou mais de 75 mil cópias de seus softwares em todo Brasil e conta hoje com a parceria de mais de 100 canais de distribuição no país. Os distribuidores são compostos por profissionais atualizados com certificação e qualificados para prestar suporte, treinamento, implantação, levantamento de necessidades específicas de cada cliente. Atualmente a empresa conta em sua sede com 91 colaboradores, destes, $92 \%$ possuem curso superior (graduação e pós-graduação).

Seu principal produto é o Sistema Radar Empresarial, um Sistema de Gestão Integrada ERP, que compreende um conjunto de subsistemas para atender grandes, médias e pequenas empresas de diferentes setores produtivos (Indústria, comércio e prestadoras de serviços).

A WK sempre se pautou pela qualidade na solução de seus produtos e serviços, com destaque no atendimento prestado ao cliente. Esse atendimento visa não somente foi concebido para resolver o problema específico de um de seus softwares, mas principalmente procura envolver o usuário na solução. Dessa forma a WK busca desenvolver o seu cliente e, com isso, conquistar sua fidelização.

\section{Análise dos Resultados}

A análise e interpretação dos dados apresentados obedecem às relações de descritividade estatística que os números da pesquisa permitem. Essa análise permite demonstrar, na visão do Marketing de Relacionamento, os fatores de satisfação considerados importantes no atendimento pelos clientes e, cruzando com a visão dos dirigentes, para identificar as estratégias adotadas pela organização em relação a cada quesito investigado.

\subsection{Qualidade do Atendimento: Avaliação e Estratégias Adotadas}

No quesito qualidade de atendimento recebido foi perguntado como o cliente se sente em relação a este quesito, levando-se em consideração os aspectos cordialidade, respeito, educação, cortesia pessoal e presteza na realização do atendimento. O gráfico a seguir ilustra as respostas obtidas.

Gráfico 1-Qualidade do atendimento recebido

Totalmente insatisfeito
Insatisfeito
Indiferente
Satisfeito
Totalmente satisfeito


Neste quesito, observa-se um percentual expressivo de satisfação percebida pelo cliente com percentual de mais de $95 \%$ de clientes satisfeitos e totalmente satisfeito. Ao se cruzar o resultado desta pergunta com a opinião dos dirigentes da empresa percebe-se que esta é uma questão estratégica para a WK. Nesse sentido, eles informaram que a empresa investe continuamente em treinamento da equipe de suporte para prestar um serviço completo e assim, possibilitando fidelizar o cliente. Outro aspecto importante levantado foi que a qualidade é discutida e acompanhada durante o processo da prestação de serviço. Adicionalmente, a equipe de suporte realiza reuniões freqüentes em que são tratados aspectos relacionados ao atendimento prestado e de como este pode ser aperfeiçoado continuamente. Este tipo de atitude por parte da empresa está em sintonia com o que prega Stone (1998) em que os clientes, além de ficarem satisfeito em obter o produto, esperam um padrão razoável de atendimento dos fornecedores.

\subsection{Agilidade: Avaliação e Estratégias Adotadas}

O gráfico a seguir, ilustra a percepção dos clientes sobre os aspectos como: agilidade, rapidez na solução do problema, responsabilidade e credibilidade com os compromissos assumidos com o cliente.

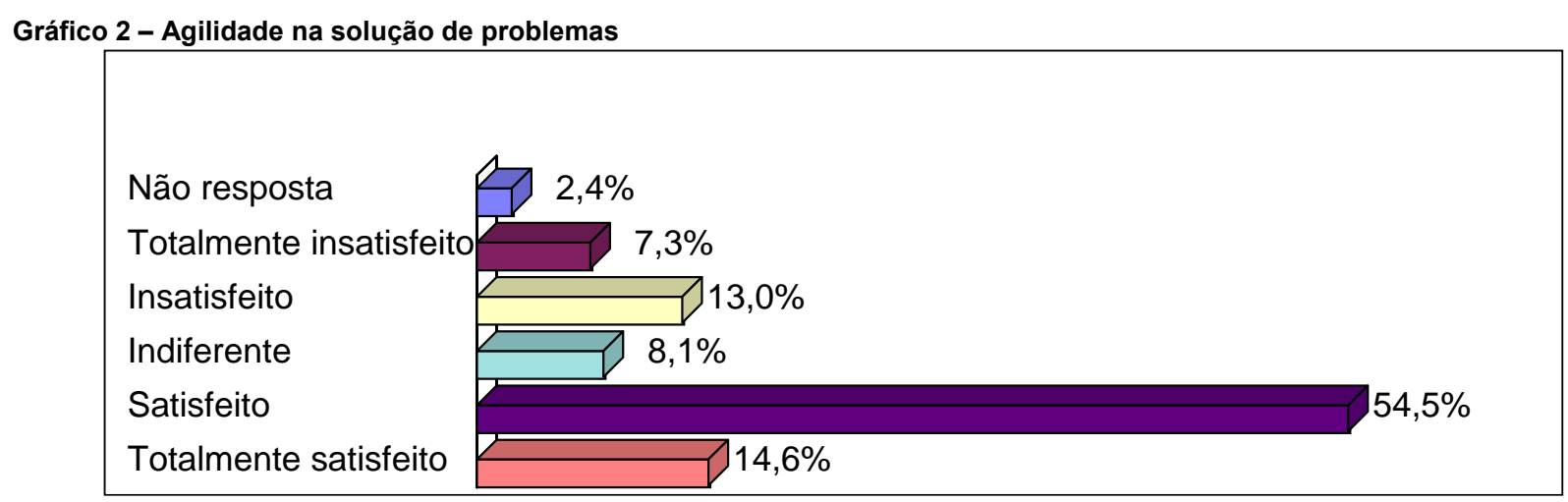

Em termos de agilidade, obteve-se um grande número de clientes satisfeitos $(54,5 \%)$ e totalmente satisfeitos $(14,6 \%)$ o que representa um montante superior a 70\%. Ao cruzar este dado com as respostas dos dirigentes, verificamos que essa agilidade é em decorrência do fato de a WK utilizar um sistema de informação baseado no conceito do CRM, em que são registrados todos os atendimentos prestados aos seus clientes. À medida que o cliente vai expondo seu problema ou dúvida, o atendente pesquisa no banco de dados se há algum registro relacionado. Se o problema não tiver registro e dependendo de sua gravidade, aciona-se o setor de desenvolvimento para que este providencie uma solução no menor espaço de tempo possível. O sistema de suporte é bastante flexível, permite a qualquer atendente pesquisar de diversas formas algum registro independente de quem fez o atendimento anteriormente. Assim, fica evidente que o CRM utilizado pela WK serve como um facilitador do contato com o cliente, nos moldes do que Brown (2001) discute.
Destaca-se a política utilizada pela A WK Sistemas em atender todas as ocorrências em no máximo 24 horas. Isto faz com que toda a equipe tenha comprometimento em prestar um atendimento rápido e ágil. Dessa forma, busca aperfeiçoar cada vez mais os seus processos internos para ganhar agilidade e produtividade na solução dos problemas do cliente.

Finalmente, percebemos que a WK utiliza a TI para atender seus clientes de forma efetiva. Stone (1998) destaca que investir em TI diminui os custos de comunicação, contribuindo de forma mais efetiva para a concepção e aprimoramento de produtos e serviços.

\subsection{Competência nas Soluções Apontadas: Avaliação e Estratégias Adotadas}

Em relação à competência na solução apontada pelo pessoal de atendimento e reconhecida pelos clientes, o gráfico a seguir ilustra os resultados. 
Gráfico 3 - Competência nas soluções apontadas

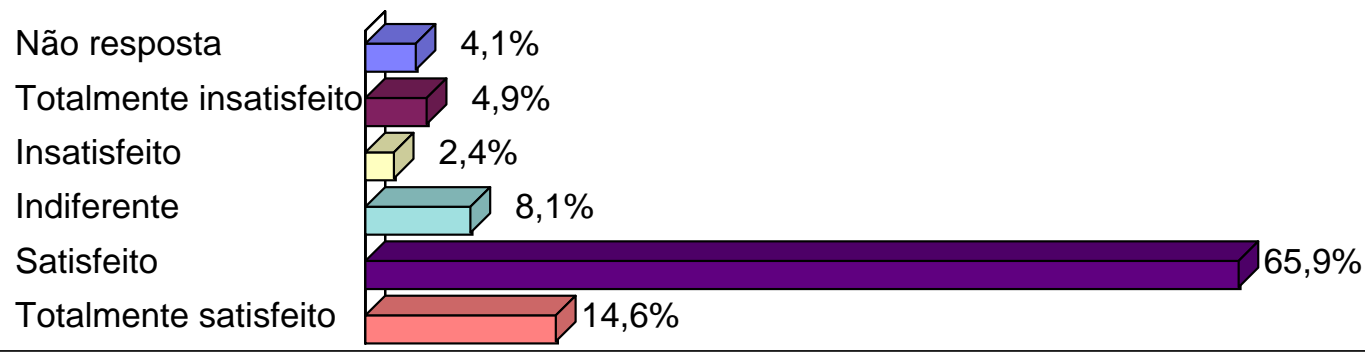

No aspecto da Competência, nas soluções apresentadas aos clientes, obteve-se um percentual elevado de clientes satisfeitos $(65,9 \%)$ e totalmente satisfeitos $(14,6 \%)$ na ordem de $80,5 \%$. Este percentual reflete as ações tomadas pela WK Sistemas no sentido de realizar treinamentos interno da equipe de suporte (já discutido anteriormente). Nesse ponto, cabe destacar que os professores que ministram esse treinamento trabalham em parceria com os desenvolvedores do sistema. Isso possibilita, por um lado, um melhor conhecimento dos recursos do sistema; por outro, um feedback mais efetivo para corrigir possíveis falhas nos módulos do sistema ou facilidades de uso apontadas pelos usuários, no caso a equipe de suporte.

\subsection{Rapidez no Atendimento: Avaliação e Estratégias Adotadas}

Em relação à questão sobre a rapidez no atendimento o gráfico a seguir ilustra os resultados obtidos para esta pergunta.

Gráfico 4 - Atendimento - disponibilidade e rapidez no atendimento

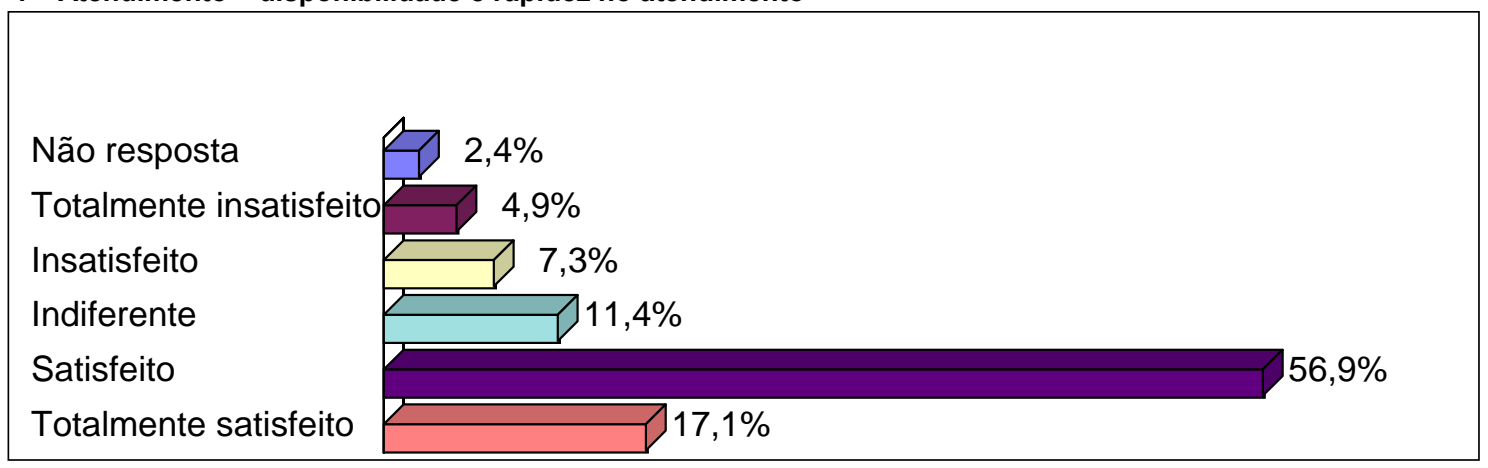

Verificamos no gráfico 4 que $74 \%$ dos clientes sentem-se satisfeitos $(56,9 \%)$ totalmente satisfeito $(17,1 \%)$ com o atendimento prestado pela WK sistemas. Ao perguntarmos para os dirigentes da WK o porquê desse percentual, verificamos que ela disponibiliza oito funcionários que ficam à disposição dos clientes para o atendimento via web (chat e e-mail) e telefônico. Caso exista uma sobrecarga no número de solicitações, a empresa possui a equipe de testes e os gerentes de produtos para auxiliar no atendimento ao cliente.

Os atendimentos são priorizados conforme a gravidade do problema. São considerados suportes críticos quando o cliente não consegue trabalhar com o sistema em virtude de alguma falha de funcionamento e precisa de uma solução urgente. Nessa hora, aciona-se imediatamente o responsável pelo setor de desenvolvimento para agilizar a correção e solucionar o problema para o cliente.

Outro aspecto a ser considerado, é que a WK Sistemas incentiva o compartilhamento de informações entre os funcionários. Essa troca constante de informações possibilita a rapidez no atendimento. Ademais, isso propicia aos funcionários uma aprendizagem mais rápida das funções do sistema e possíveis soluções para os problemas já ocorridos com os clientes. Como resultado, a equipe esta sempre se atualizando e trocando informações, pois de acordo com os dirigentes da WK, o melhor atendimento é aquele que supera as expectativas do cliente, que muitas vezes devem ir além daquelas supridas pelo produto em si. 
6.5 Apoio Recebido da Equipe de Suporte: Avaliação e Estratégias Adotadas
Sobre a questão do apoio recebido da equipe de suporte após apresentada a solução do problema (pós venda), o Gráfico 5 ilustra os resultados:

\section{Gráfico 5 - Apoio prestado ao cliente após a solução apresentada}

Não resposta
Insatisfeito
Satisfeito
Totalmente insatisfeito

No gráfico acima, constatamos que mais de $80 \%$ dos clientes estão satisfeitos $(68,9 \%)$ e de totalmente satisfeitos (11,4\%). Em pesquisa interna, verificamos que a WK Sistemas realiza um contato do pós serviço prestado, para identificar possíveis oportunidades de melhorias e também de checar a eficácia da solução apresentada pela equipe. Via de regra, esse retorno é realizado pela pessoa que atendeu o cliente da primeira vez, pois esta já possuir o histórico de solução apresentada. Caso este atendente não esteja na empresa, o coordenador do suporte repassa o problema e a solução para outro funcionário. Ademais, se for verificado que está havendo alguma concentração de chamados referente a determinado problema, um membro da equipe é mobilizado para encontrar uma solução mais completa, que envolve o cliente e, se necessário, a equipe de desenvolvimento.

Para dar suporte a essa atividade, a WK utilizase de seu sistema de CRM para que todas as informações sejam registradas. Assim, há uma atualização natural do banco de dados com o histórico de cada atendimento e a solução apresentada. A utilização do CRM pela WK permite que ela obtenha vantagem competitiva, pois consegue acessar informações dos clientes de forma rápida o que possibilita a manutenção de um estreito relacionamento com ele. A maneira como a WK executa o seu Marketing de Relacionamento está em sintonia com o que pregam os autores Szafir-Goldstein e Souza (2003) e Stair e Reynolds (2009).

\subsection{Custo e Benefício dos Produtos e Serviços Prestados}

A percepção dos clientes em relação ao custo benefício do serviço prestado pela WK pode ser visualizada no gráfico a seguir:

Gráfico 6 - Custo benefício dos produtos e serviços prestados

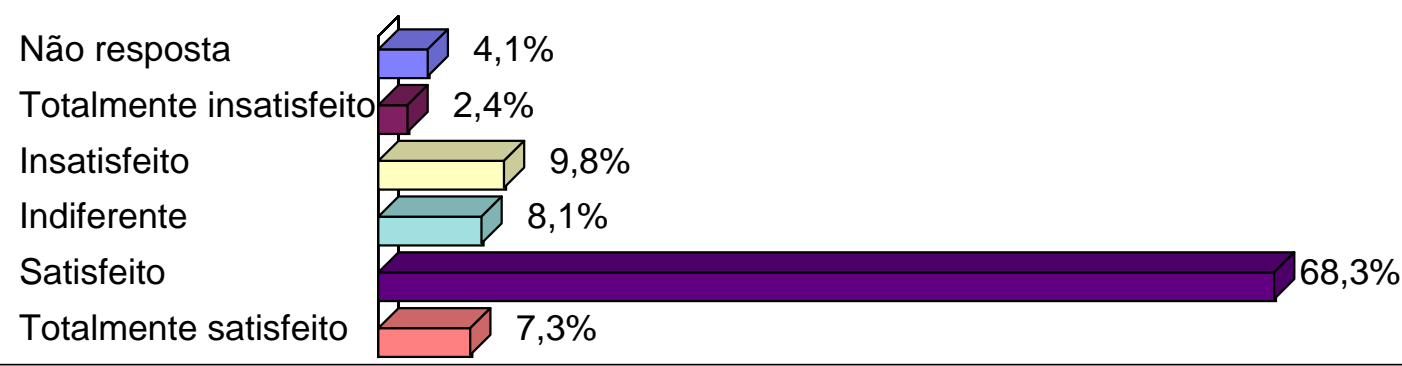

O gráfico 6 indica que 75,6\% dos clientes estão satisfeitos $(68,3 \%)$ ou totalmente satisfeito $(7,3 \%)$ com relação ao custo benefício do serviço adquirido. Ao analisarmos este dado mais de perto, cruzando com as informações obtidas internamente da empresa, identificou-se que a WK realiza 
constantes melhorias nos produtos e processos, por meio de otimizações, implementação de recursos novos, nos mais variados processos e relatórios desenvolvidos em tecnologia de ponta com o objetivo de facilitar o dia-a-dia de seus usuários.

Outro aspecto importante, é que os sistemas da WK são desenvolvidos em banco de dados projetados para dar apoio à tomada de decisão, dando apoio nos três níveis gerenciais (operacional, tático e estratégico) apontados por Laudon e Laudon (2001) e Cortêz (2008). Ademais, como o sistema desenvolvido pela WK foi projetado para apresentar informações precisas, provenientes das diferentes áreas das organizações. Ele oferece como resultados uma visão clara e abrangente das operações que estão sendo realizadas nas empresas usuárias.

\subsection{Profissionalismo e comprometimento da equipe de suporte?}

Em relação ao profissionalismo e comprometimento da equipe de suporte, as respostas dos clientes da WK podem ser visualizadas no gráfico 7 :

\section{Gráfico 7 - Profissionalismo e compromisso da equipe de suporte}

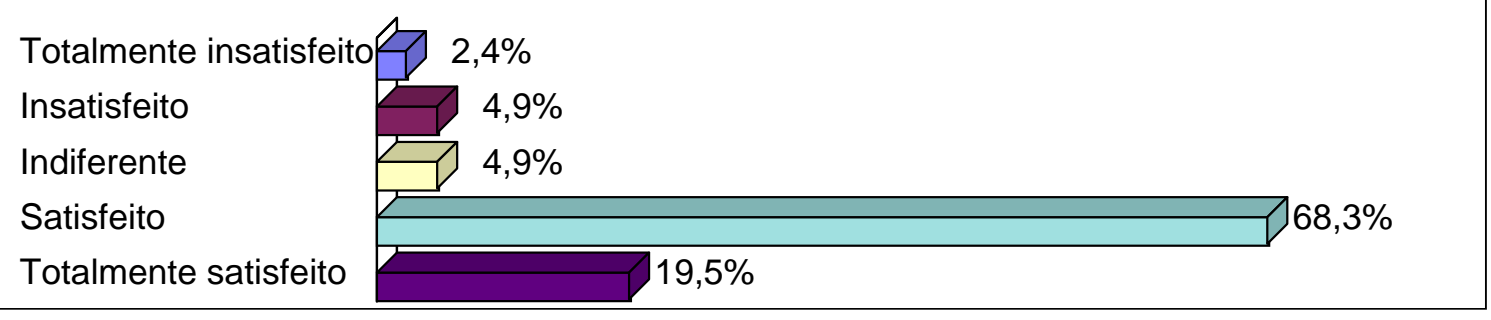

O profissionalismo demonstrado pela equipe de suporte da WK vem sendo reconhecido pelos clientes, sendo que praticamente $88 \%$ deles se consideram satisfeitos $(68,3 \%)$ e totalmente satisfeitos $(19,5 \%)$. Isto se reflete em virtude da política da WK em desenvolver seus colaboradores. Nesse sentido, destacam-se os treinamentos internos oferecidos pela empresa em: gestão de projetos, gestão do contato com o cliente, novas tecnologias, entre outros. Ademais a WK possui um programa de incentivo para que os colaboradores cursem uma universidade, ou, para os que já estão formados, existe a possibilidade de continuarem os estudos em programas de educação continuada (cursos em nível de pós-graduação MBA e mestrado). Isso ficou evidente ao se constatar que 91\% dos colaboradores da WK possuírem curso superior.

Ademais, nas entrevistas, verificamos que essa política segue a estratégia para prestar atendimento de alta qualidade, buscando a satisfação e a fidelização do cliente. Assim, a estratégia adotada pela WK está alinhada com o que afirmam Kotler e Keller (2006) e De Toni et. al. (2008), em que a satisfação é considerada um dos principais fatores para a manutenção de clientes.

\section{CONCLUSÕES}

O marketing de relacionamento é considerado uma filosofia empresarial que prevê a construção e a manutenção de relacionamentos individuais com os clientes, vislumbrando um horizonte de longo prazo. Nesse sentido, a empresa necessita conhecer melhor os clientes, para oferecer serviços adequados aumentando o relacionamento com ele (D'ANGELO; SCHNEIDER; LARÁN, 2006). Para tanto, o uso da TI é fundamental, pois ela permite criar, sustentar, desenvolver e interpretar um relacionamento de marketing com os clientes a custos menores (STONE, 1998).

Conforme apontado neste estudo, compreender o comportamento do consumidor hoje é um fator determinante para o sucesso de uma organização. $E$, uma das principais ferramentas de marketing disponíveis é Marketing de Relacionamento, pois aborda como a empresa se relaciona e cria valor para os clientes. Assim, o objetivo deste trabalho foi identificar fatores de satisfação considerados importantes pelos clientes no atendimento prestado por uma fábrica de Software e como, em função deles, ela define suas estratégias de marketing de relacionamento.

Os resultados apresentados na pesquisa quantitativa com os clientes indicam que a WK Sistemas possui bons indicadores em relação à 
percepção dos clientes nos seguintes indicadores: a) qualidade do atendimento; b) agilidade e competência na solução de problemas; c) disponibilidade e rapidez no atendimento; d) apoio prestado após a solução apresentada; e) custo benefício dos serviços prestados; e f) profissionalismo e compromisso da equipe de suporte. Ao analisar esses resultados mais a fundo e cruzando-os com a pesquisa qualitativa realizada internamente com os dirigentes, verificamos que esse resultado positivo deveu-se ao fato de a empresa possuir consciência da importante do marketing de relacionamento e de alinhar sua estrutura organizacional e tecnológica para atender o cliente com a qualidade esperada.

Adicionalmente, identificamos que a capacidade desenvolvida pela WK para prestar o serviço prometido de maneira individualizada vem se mostrando essencial para ela mantenha sua base de cliente. Aliados a isso, verificamos a importância da política de valorização tanto do cliente externo quanto do interno, o que tem possibilitado a WK cumprir a estratégia de oferecer produtos $\mathrm{e}$ serviços com alta qualidade visando à fidelização dos seus clientes.

Finalmente, constatou-se que existe espaço para melhorias nos serviços prestados pela WK em praticamente todos os itens, em especial para àqueles que se referem à agilidade e a rapidez no atendimento das solicitações dos clientes. Assim, identificamos que atender as expectativas dos clientes é uma tarefa árdua e contínua e, o uso do Marketing de Relacionamento aliando às ferramentas de TI pode ser uma das opções a serem consideradas.

\section{Referências}

AGTECH Soluções. Política nacional de informática. 25/04/2007. Disponível em: http://www.agtech.com.br/index.php?action=noticia \&idioma=pt\&id=991\&pag=3. Acesso em: 01/07/2009.

\section{ALBERTÃO, S. E. ERP - sistema de gestão} empresarial: metodologia para avaliação, seleção e implantação. 2. ed. São Paulo: Iglu, 2005.

BROWN, S.A. CRM - customer relationship management. São Paulo: Makron Books, 2001.

CHIZZOTTI, A. Pesquisa em ciências humanas e sociais. São Paulo: Cortez, 1995.

CRESWELL, J. W. Research design: qualitative, quantitative, and mixed method approaches. 2. ed. Thousand Oaks: Sage, 2003.
CORTÊZ, P. L. Administração de sistemas de informação. São Paulo: Saraiva, 2008.

D'ANGELO, A. C.; SCHNEIDER, H.; LARÁN, J. A. Marketing de relacionamento junto a consumidores finais: um estudo exploratório com grandes empresas brasileiras. Revista de Administração Contemporânea, v. 10, n. 1, p. 73-93, Jan./Mar. 2006.

DE TONI, D. et al. A imagem do comércio varejista e a satisfação dos consumidores: Um Estudo Exploratório Ambientado em uma Cidade da Serra Gaúcha. In: ENCONTRO DA ASSOCIAÇÃO NACIONAL DOS PROGRAMAS DE PÓSGRADUAÇÃO EM ADMINISTRAÇÃO, 32., 2008, Rio de Janeiro. Anais... Rio de Janeiro: ANPAD, 2008.

Federação das Indústrias do Estado de Santa Catarina - FIESC. Santa Catarina em dados 2008. Florianópolis. v. 18. Disponível em: http://www2.fiescnet.com.br/web/pt/site/pei/produto s/show/id/46. Acesso em: 01/07/2009.

GODOY, ARILDA S. Introdução à pesquisa qualitativa e suas possibilidades. Revista de Administração de Empresas, v. 35, n. 1, 1995.

GRÖNROOS, C. Marketing, gerenciamento e serviços: a competição por serviços na hora da verdade. Rio de Janeiro: Campos, 2009.

KOTLER, P.; KELLER, K. L. Administração de marketing. São Paulo: Prentice Hall, 2006.

LAS CASAS, A. L. Marketing de serviços. São Paulo: Saraiva, 2006.

LAUDON, K. C.; LAUDON, J. P. Gerenciamento de sistemas de informação. 3. ed. Rio de Janeiro: LTC, 2001.

LOVELOCK, C. Serviços: marketing e gestão. São Paulo: Saraiva, 2001.

LOURENÇO, C.; PEREIRA, J. R.. Relações de troca sob a ótica do marketing de relacionamento e da teoria da dádiva. In: Encontro da Associação Nacional dos Programas de Pós-Graduação em Administração, 31., 2007, Rio de Janeiro. Anais... Rio de Janeiro: ANPAD, 2007.

MCKENNA, R. Marketing de relacionamento. 9. ed. São Paulo: Campus, 1992.

MARINHO, P. O que é marketing de relacionamento. Disponível em <http://www. intermanagers.com.br>. Acesso em 14 ago 2002.

MASON, Jennifer. Qualitative researching. London: Sage, 1997. 
MOWEN, J. C.; MINOR, M. S. Comportamento do consumidor. São Paulo: Prentice-Hall, 2003.

NUNES, Arthur Pereira. Política industrial e tecnológica e de comércio exterior: software e serviços. Seminário FINEP - PITCE - Software e Serviços. Rio de Janeiro, 2004. Disponível em: http://ce.mdic.gov.br/SOFTWARE/MCT\%20\%20arthur_pereira_nunes_politica_ industrial_software.pdf. Acesso em 01/07/2009.

O'BRIEN, J. A. Sistemas de Informação e as decisões gerenciais na era da Internet. São Paulo: Saraiva, 2002.

POLLONI, E. G. F. Sistemas de informação: estudo de viabilidade. São Paulo: Futura, 2000.

SEBRAE - Serviço Brasileiro de Apoio às Micro e Pequenas Empresas. Micro empresas. Disponível em <http://www.sebrae.com.br/> Acesso em: 31 maio 2007.

SOFTEX. Pesquisa de satisfação softex ano 2000. Disponível em <http://www.softex.br/ > Acesso em: 07 out 2002.

SAMARA, B. S.; BARROS, J. C. de. Pesquisa de marketing: conceitos e metodologia. 2. ed. São Paulo: Makron Books, 1997.

SETH, J. N., MITTAL, B., E NEWMAN, B. I. Comportamento do cliente. São Paulo: Atlas, 2001.

STAIR, M. R.; REYNOLDS, G. W. Princípios de sistemas de informação. 6. ed. São Paulo: Cengage Learning, 2009.

STONE, M.; WOODCOCK, N. Marketing de relacionamento. São Paulo: Littera Mundi, 1998.

SZAFIR-GOLDSTEIN, C.; SOUZA, C. A.

Tecnologia da informação aplicada à gestão empresarial: um modelo para a empresa digital. In: SEMINÁRIOS EM ADMINISTRAÇÃO FEA-USP, 2003. Anais do VI SEMEAD. São Paulo: FEAUSP, 2003.

TURBAN, E. RAINER, JR., R. K.; POTTER, R. E. Administração de tecnologia da informação. Rio de Janeiro: Campus, 2003.

VERGARA, S. C. Projetos e relatórios de pesquisa em administração. São Paulo: Atlas, 2003. 